\title{
RESPONSABILIDADE SOCIAL CORPORATIVA: um Estudo de Caso de Empresas Exportadoras Cearenses do Setor CalÇAdista
}

Bruno Cals de Oliveira Graduandoem Administração Estudante-Bolsista de Iniciação Científica CNPq/UFC brunocalsadm@yaboo.com.br

Joana D'Arc de Oliveira MestreemEconomia Professora Adjunta da Universidade Federal do Ceará jdarc42@terra.com.br

\section{Leonel Gois Lima Oliveira \\ Graduandoem Administração leonelgoi@gmail.com}

\section{Marcelle Colares Oliveira}

Doutorado em Controladoriae Contabilidadepela USP Professora Adjunta da Universidade Federal do Ceará-UFCe Professora Titular da Universidade de Fortaleza-UNIFOR marcellecolares@unifor.br

Marlos Costa de Andrade Graduandoem Administração marlo@edu.unifor.br

Monalisa Viana Marques

Graduandoem Ciências Contábeis monapzinha@botmail.com 


\section{RESUMO}

Os conceitos e práticas de responsabilidade social corporativa vêm ganhando espaço crescente de discussão no meio acadêmico e profissional. Procurou-se responder, neste trabalho, aos seguintes questionamentos: quais os conceitos e práticas de responsabilidade social corporativa adotados pelas empresas exportadoras cearenses? Que objetivos essas empresas aderem a tais conceitos e práticas? A escolha do setor justifica-se por sua representatividade na economia do Ceará. Trata-se de uma investigação exploratória, com abordagem qualitativa, que se realizou pesquisa bibliográfica e documental e estudo de caso múltiplo, para trazer uma melhor compreensão sobre o assunto. As empresas estudadas foram Grendene S/A, Dakota Nordeste S/A e Vulcabrás do Nordeste S/A. Foram colhidos dados nas suas Demonstrações Contábeis publicadas em meio impresso e nos seus sites. Concluiu-se que as empresas cearenses do setor calçadista estudadas utilizam diversas práticas de responsabilidade social corporativa e o enfoque de suas ações visa, principalmente, ao marketing social e à produtividade interna.

Palavras-Chave: Responsabilidade Social Corporativa (RSC), Adoção dos Conceitos de RSC, Estratégias Corporativas, Empresas Exportadoras, Setor Calçadista.

\section{ABSTRACT}

The concepts and practices of Corporate Social Responsibility come earninggrowing space of argument in professional and academic environment. It has tried to answeer, in this work, the following question: Which concepts and practices of Corporate Social Responsibility/CSR) areadopted by the exporting companies residents of Ceara'? Which objective those companies adhere those concepts and practices of CSR? The choice of the sector justifies itself by its importance in theeconomy of Ceara. This is an exploratoryinquiry, with qualitativeapproach, that was carried out researches of bibliography, documental and study of multiple case, to bring abettercomprehension about the topic. The companiesstudied were Grendene S/A, Dakota NordesteS/A and Vulcabrás do NordesteS/A. Thefacts were reaped in their Accounting Demonstrationspublished in printed environmentand in the their sites. It concluded that the shoes companies residents of ceará studied, do diverse practices of CSR and that the approach of its actions aims, mainly, thesocial marketing and the internal productivity.

KEYWORDS: Corporate Social Responsibility(CSR), Corporate Strategy 


\section{INTRODUÇÃO}

A responsabilidade social corporativa consiste em um comprometimento da empresa para com a sociedade, envolvendo estratégias organizacionais, visando à utilização responsável dos recursos produtivos, a satisfação dos funcionários, o bem-estar da sociedade e a preservação do meio ambiente.

Nesse contexto, a responsabilidade social corporativa reflete o comprometimento da gestão da empresa com a realização de atividades que, mesmo não estando ligadas ao objeto social dos seus negócios, são priorizadas pela organização, com o objetivo de atingir a melhoria da qualidade de vida de seus empregados e da sociedade, adotar os valores éticos por ela defendidos, agir de maneira ambientalmente correta, bem como garantir a própria continuidade da empresa.

Para Melo Neto e Froes (2001, p. 133), a empresa socialmente responsável atua em três vetores éticos.

I) o vetor da adoção dos valores éticos - no qual a empresa inicia sua cultura socialmente responsável, cumprindo com suas obrigações éticas, morais, culturais, econômicas e sociais;

II) o vetor da difusão dos valores éticos - em que a empresa, já com seu padrão ético estabelecido, começa a desenvolver projetos e ações; e

III) o vetor da transferência de valores éticos - nesse momento, a empresa assume definitivamente um papel socialmente responsável. Seus projetos e ações tornam-se sustentáveis, e os resultados obtidos asseguram uma melhoria da qualidade de vida, no trabalho e na comunidade.

Segundo Carroll (citado por DAFT apud LOURENÇO; SCHRODER, 2003), uma das subdivisões da responsabilidade social empresarial é a responsabilidade econômica, que consiste na produção de bens e serviços necessários e desejados pela sociedade, a um preço que possa garantir a continuação das atividades da empresa, de forma a satisfazer suas obrigações com os investidores e maximizar os lucros para seus proprietários e acionistas.

Procurando assegurar sua continuidade, muitas empresas têm lançado mão de novas estratégias de negócios, entendendo que a implementação de esforços, em prol do benefício da sociedade, parece ser um mecanismo de diferenciação nos mercados nacional e internacional.

No Brasil, a pesquisa, realizada pelo Instituto de Pesquisa Econômica Aplicada (IPEA, 1999), com o objetivo de traçar um primeiro retrato da ação social das empresas, identificou que $59 \%$ das empresas, com um ou mais empregados, declararam realizar algum tipo de ação social para a comunidade, em caráter voluntário, ou seja, das 782 mil empresas do país, 462 mil contribuem no campo social. As contribuições envolvem desde promoção de grandes projetos mais estruturados até doações eventuais a pessoas carentes ou a instituições que executam projetos sociais.
Os problemas socioeconômicos brasileiros, por exemplo, baixo poder aquisitivo da população e sistemas educacional e de saúde deficientes, têm motivado o surgimento, no Brasil, de empresas socialmente responsáveis.

Diante desse quadro, procurou-se responder, neste trabalho, aos seguintes questionamentos: quais os conceitos e as práticas de responsabilidade social corporativa adotados pelas empresas exportadoras cearenses do setor de calçados? Com que objetivo essas empresas adotam estes conceitos e práticas?

Partiu-se do pressuposto de que, se a adoção de conceitos e se práticas de responsabilidade social corporativa visa, principalmente, melhorar a imagem e a produtividade interna das empresas, as empresas cearenses exportadoras do setor de calçados adotam esses conceitos e práticas para obter vantagens com isso.

O objetivo geral da pesquisa é investigar os conceitos e as práticas de responsabilidade social corporativa adotados pelas empresas cearenses exportadoras do setor de calçados, evidenciando os objetivos que levam estas empresas a adotar esses conceitos e práticas.

Com esse estudo, pretende-se fomentar a discussão do tema tanto em termos de conscientização do empresariado, com relação à necessidade de inserção dos conceitos e das práticas de responsabilidade social corporativa na gestão de sua empresa, quanto dos vetores éticos que estão sendo seguidos pelas empresas exportadoras cearenses do setor calçadista, trazendo uma contribuição tanto para a área de conhecimento das Ciências Sociais Aplicadas e Estratégia e Competitividade Internacional, bem como para a totalidade da sociedade.

Outro aspecto relevante da pesquisa diz respeito à difusão desse tipo de estudo científico no meio universitário, ambiente propício a essa discussão nos cursos de graduação, de especialização e de mestrado de áreas relacionadas.

Por fim, esse estudo pretende contribuir para a reflexão sobre a necessidade de inserção do assunto Responsabilidade Social Corporativa nas grades curriculares.

O estudo justifica-se pela importância da discussão do tema responsabilidade social corporativa nos meios acadêmico e profissional e pela representatividade do setor calçadista do Ceará que se posiciona entre os cinco maiores do Brasil.

\section{RESPONSABILIDADE SOCIAL CORPORATIVA}

Bianchini (2005) afirma que Responsabilidade Social Corporativa é um conceito que surgiu na metade do século XIX graças à contribuição de J.S Mill, um ponto de referência do pensamento liberal.

Contudo o conceito de Responsabilidade Social Corporativa ganhou espaço a partir do momento em que as questões ambientais e sociais passaram a ser temas de cres- 
cente preocupação da sociedade, na década de 70, quando se intensificou o debate acerca do desenvolvimento, culminando na criação do conceito de desenvolvimento sustentável, amplamente difundido a partir da Conferência Mundial para o Meio Ambiente e Desenvolvimento, conhecida como ECO 92 (SAGE, 2004).

Neste sentido, fornecedores, clientes, trabalhadores, comunidades vizinhas, órgãos governamentais e acionistas tiveram ampliadas as ocasiões de intervenção em projetos e na gestão das organizações. Várias normas, como a SA8000 e a AA1000, bem como os selos, as certificações internacionais e as nacionais são utilizados na regulamentação das empresas (SAGE, 2004).

\subsection{Conceitos de responsabilidade social corporativa}

A responsabilidade social corporativa é tida como uma forma de relação entre a empresa com a sociedade, envolvendo estratégias para a concretização de negócios, visando à satisfação desde os funcionários até o bem-estar da sociedade. (OLIVEIRA et al, 2004).

Para Jamillo e Angel (apud TENÓRIO, 2004, p. 32), "Responsabilidade Social pode ser também o compromisso que a empresa tem com o desenvolvimento, bem-estar e melhoramento da qualidade de vida dos empregados, suas famílias e comunidade em geral".

Para Melo Neto e Froes (2001), responsabilidade social de uma empresa é a decisão de participar mais diretamente das ações comunitárias na região a que pertence, procurando minorar possíveis danos ambientais decorrentes do tipo de atividade exercida. Os autores acrescentam que a Responsabilidade Social Corporativa é o comprometimento permanente dos empresários de adotar um comportamento ético e contribuir para o desenvolvimento econômico, melhorando, simultaneamente, a qualidade de vida das famílias dos empregados, da comunidade local e da sociedade no geral.

Para o Instituto Ethos, responsabilidade social é uma forma de conduzir os negócios da empresa de tal maneira, que a torna parceira e co-responsável pelo desenvolvimento social. A empresa socialmente responsável é aquela que possui a capacidade de ouvir os interesses das diferentes partes (acionistas, funcionários, prestadores de serviço, fornecedores, consumidores, comunidade, governo e ambientalistas) e conseguir incorporá-los no planejamento de suas atividades, buscando atender às demandas de todos e não apenas dos acionistas ou proprietários.

De acordo com Dacin (1997 apud PEIXOTO, 2005), para criar uma boa reputação entre seus diferentes públicos, as empresas devem demonstrar efetividade organizacional e performance social. Efetividade organizacional é definida por Dacin como a capacidade das empresas em produzir e entregar o produto ou o ser- viço prometido ao cliente. Já a performance social está relacionada à responsabilidade social corporativa, ou seja, o caráter da empresa associado a importantes aspectos sociais, como um foco em meio ambiente, comprometimento com diversidade de contratação e de promoção, envolvimento comunitário, patrocínio de atividades culturais e filantropia corporativa.

Ao buscar-se melhor compreensão do que representa essa tendência, é fundamental entender em que se sustenta o princípio da responsabilidade social, porquanto algumas empresas restringem o conceito de cidadania a doações em ações de caráter humanitário, sem considerar que esta deverá expressar-se num conjunto de dimensões que transcendem as ações filantrópicas.

aquela que leva em conta os problemas sociais locais existentes no país onde opera; que entende ser a incorporação de populações excluídas do mercado, necessário para o próprio desenvolvimento empresarial; [...] que cria práticas refletidas por valores éticos em toda empresa; que promove a conservação dos recursos naturais e estimula a participação de seus colaboradores na vida da comunidade; e que respeita a relação com os participantes de todas as cadeias de produção. (RABAÇA, 2001 apud VASCONCELOS, 2002, p. 27)

Nesse sentido, o presidente do Instituto Ethos, Oded Granjew, considera que o conceito é mais amplo.

\footnotetext{
Responsabilidade social como um modelo de gestão que extrapola a lei e a filantropia, passando da relação socialmente compromissada da empresa para abranger todas as relações com seus funcionários, clientes, acionistas, concorrentes, meio ambiente e outras organizações. (GRANJEW, 2000 apud VASCONCELOS, 2002, p.28).
}

Responsabilidade social, de fato, abrange múltiplas dimensões, mas, na verdade, seria uma busca de interagir de forma positiva com os elementos com que as empresas se relacionam. Apesar de não haver uma definição única e comum de responsabilidade social corporativa, ela geralmente se refere à tomada de decisões empresariais vinculada aos valores éticos, ao cumprimento dos requisitos legais e ao respeito às pessoas, às comunidades e ao meio ambiente.

Em suma, a responsabilidade social corporativa é o reflexo do comprometimento da gestão de uma empresa, na realização de atividades que, mesmo não estando ligadas ao objeto social dos seus negócios, são priorizadas pela organização, com o objetivo de atingir a melhoria da qualidade de vida de seus empregados e da sociedade, bem como garantir a própria continuidade da empresa. O conceito de Responsabilidade Social é amplo, e há uma grande variedade de definições para o termo. 


\section{AS DIFERENTES VISÕES DA RESPONSABILIDADE SOCIAL}

A visão clássica das empresas exclusivamente maximizadoras de lucros vem perdendo força, à medida que as práticas de responsabilidade social avançam e tornam-se estratégias importantes para o atual contexto das organizações.

De acordo com Milton Friedman (apud FORMENTINI, 2004), vencedor do Prêmio Nobel de Economia de 1976, a principal obrigação da empresa é o seu desempenho econômico, ou seja, utilizar seus recursos e engajar-se em ações destinadas a aumentar seus lucros, tanto quanto possível, dentro das regras do jogo, atuando em mercado livre e competitivo sem fraudes. Contudo, ao contrário de Friedman, conforme Carroll (1979) cita, outros estudiosos tinham entendimento diferente, por exemplo, McGuire defendia que responsabilidade social significava que a empresa deveria ir além dos requisitos econômicos e legais; já para Ackerman e Bauer, responsabilidade social era gerar caminhos para uma resposta social positiva.

Sendo um conceito recente, responsabilidade social tornou-se uma nova área de conhecimento do mundo empresarial. Para Melo Neto e Froes (2001, p.42), existem diferentes visões a seu respeito, abordando os seguintes temas: ética, marketing e produtividade e socioambiental:

Ética: visa à responsabilidade social como atitude e comportamento ético e responsável. É dever da empresa ter transparência, ética e responsabilidade em suas ações. Há também a incorporação de valores, visando a sua sustentabilidade.

Marketing e Produtividade: visa à responsabilidade social como estratégia empresarial. Valorização do seu negócio como estratégia de aumentar seu faturamento. Há uma visão de marketing institucional. As práticas de responsabilidade social são amplamente divulgadas para mostrar aos consumidores suas ações sociais.

Socioambiental: visa à responsabilidade social como estratégia de relacionamento com a comunidade, visando ao seu desenvolvimento, como modo de promover a cidadania individual e coletiva e como responsabilidade ambiental.

\subsection{A ética na}

responsabilidade social corporativa

Ética é a base da Responsabilidade Social e se expressa através dos princípios e dos valores adotados pela organização. Seu objetivo é desenvolver a sociedade e a comunidade a partir de novas inserções e parcerias, envolvendo outros agentes, como as empresas, as ONG's, as entidades fi- lantrópicas, as associações comunitárias e o próprio Estado (Melo Neto e Froes, 2001).

A ênfase é na legitimação social empresarial, cujo objetivo é legitimar a ação das empresas, enfatizando o seu caráter altruísta e o seu elevado compromisso social.

As ações de RSC buscam aprimorar as relações das empresas com seus diversos públicos, inseri-las devidamente no âmbito social das comunidades vizinhas e, sobretudo, reforçar a atuação das ONG's, das associações comunitárias, das entidades filantrópicas e do governo local, seus principais parceiros.

A dimensão ética ganhou tal importância no âmbito da responsabilidade social corporativa, que hoje é possível fazer uma avaliação específica do que denominamos comportamento ético-social da empresa.

Pode-se considerar a inclusão do comportamento ético empresarial como uma dimensão do exercício da responsabilidade social corporativa. (Melo Neto e Froes, 2001).

\subsection{Marketing social, produtividade e responsabilidade social corporativa}

Para a difusão das ações sociais promovidas no âmbito de uma organização podem ser utilizadas as operações de Marketing Social, fundamentais na formação da imagem da instituição, dado que as atividades relativas a responsabilidade social corporativa tem-se revelado fonte de publicidade para a empresa evidenciando sua política, suas práticas administrativas, bem como os principais fatores por ela prezados, podendo seduzir empresários e o público externo em geral, ao mesmo tempo em que parece sensibilizar os trabalhadores para uma atuação mais produtiva.

\subsubsection{Marketing Social}

Kotler (2000, p.30) define marketing como sendo "Um processo social e gerencial por meio do qual as pessoas e grupos de pessoas obtêm aquilo que necessitam e o que desejam com a criação, oferta e livre negociação de produtos e serviços de valor com outros". Essa definição envolve elementos que não se restringem a processos gerenciais, mas também a processos sociais, tais como necessidades, desejos e demandas; produtos; valor; custos e satisfação; troca, transações e relacionamentos.

As empresas tendem a utilizar medidas de ações sociais para demonstrar sua preocupação com a sociedade. Utilizam, então, do chamado Marketing Social para melhorar sua imagem perante seus clientes. Marketing Social é definido por Kotler (1978, p.287):

a implementação e o controle de programas que procuram aumentar a aceitação e uma idéia social num gru- 
po-alvo. Utiliza conceitos de segmentação de mercado, de pesquisa de consumidores, de configuração de idéias, de comunicações, de facilitação de incentivos e a teoria da troca, a fim de maximizar a reação do grupo-alvo.

O marketing social pode ser entendido como uma estratégia de mudanças comportamentais e de atitudes, que pode ser utilizada em qualquer tipo de organização, desde que esta tenha uma meta final de produção e de transformação de impactos sociais.

\subsubsection{A Gestão da Responsabilidade Social: O Foco na Produtividade do Trabalhador}

Melo Neto e Froes (2001, p.87) afirmam que as ações de gestão interna de responsabilidade social compreendem os programas de contratação, de seleção, de treinamento e de manutenção de pessoal realizados pelas empresas em benefício de seus empregados, bem como os demais programas de benefícios voltados para a participação nos resultados e no atendimento aos dependentes.

Ainda segundo Melo Neto e Froes (2001, p.87), são as seguintes as principais ações deste tipo desenvolvidas pelas empresas:

Investimentos no bem-estar dos empregados e seus dependentes (programas de remuneração e participação nos resultados, assistência médica, social, odontológica, alimentar e de transporte);

Investimentos na qualificação dos empregados (programas internos de treinamento e capacitação e programas de financiamento de cursos externos, regulares ou não, realizados por seus funcionários com vistas a sua maior qualificação profissional e obtenção de escolaridade mínima).

Os investimentos realizados através da responsabilidade social interna focam diretamente os funcionários da empresa e os dependentes dos mesmos. Algumas empresas expandem estas práticas a funcionários terceirizados, fornecedores e parceiros comerciais. (MELO NETO e FROES, 2001).

Esses investimentos visam ao bem-estar dos funcionários, dando-lhes mais prazer em trabalhar naquela empresa, aumentando, assim, sua capacidade produtiva. Com isso, ganha o funcionário, por estar trabalhando com elevado grau de satisfação, e ganha a empresa, por contar com trabalhadores mais produtivos.

\subsection{Socioambiental}

Fischer et al (2005) afirmam que muitas empresas se envolvem, de alguma forma, com questões sociais, seja do- ando recursos, seja desenvolvendo projetos sociais externos, visando à área social com uma abordagem estratégica.

Segundo o IPEA (apud FISCHER et al, 2005), 462 mil (59\%) empresas brasileiras, com um ou mais empregados, declaram realizar, em caráter voluntário, algum tipo de ação social para a comunidade. Dois terços destas empresas afirmam que a prática social é cotidiana e 39\% declara que pretende ampliar sua atuação em um futuro próximo.

No que se refere ao meio ambiente, as empresas socialmente responsáveis estão tentando minimizar os impactos ambientais estabelecendo metas compatíveis com o desenvolvimento sustentável e preservando os recursos naturais o que favorecerá as gerações futuras.

\subsubsection{Responsabilidade Social Externa}

Melo Neto e Froes (2001, p.88) afirmam que o exercício da responsabilidade social externa corresponde ao desenvolvimento de ações sociais empresariais que beneficiam a comunidade. Estas ações podem ser realizadas através de doações de produtos, equipamentos e materiais em geral, transferência de recursos em regime de parceria para órgãos públicos e ONG's, prestação de serviços voluntários para a comunidade pelos funcionários da empresa, aplicações de recursos em atividades de preservação do meio ambiente, geração de empregos, patrocínio de projetos sociais do governo e investimentos diretos em projetos sociais criados pela própria empresa.

Ainda segundo Melo Neto e Froes (2001, p.89), a responsabilidade social externa tem como foco a comunidade, através de ações sociais voltadas, principalmente, para as áreas de educação, saúde, assistência social e ecologia, visando a um maior retorno social.

\subsubsection{Meio Ambiente}

Para Berna (2005), a principal meta de uma Política Ambiental para as empresas consiste em minimizar os impactos sociais e ambientais de uma empresa e tornar sua operação ecologicamente correta.

Ainda para Berna (2005), para se conseguir uma política ambiental correta, é preciso ter quatro metas, quais sejam: a) o engajamento da empresa na luta por um novo modelo de desenvolvimento que seja ambientalmente sustentável, socialmente justo e viável economicamente; b) a valorização da imagem corporativa tanto interna quanto externamente; c) a atuação em parceria com outras empresas, ONGs, instituições, universidades, prefeituras, comunidades; e, d) a demonstração para as demais empresas do Setor do compromisso com a sustentabilidade ambiental.

Dentro desse contexto, as empresas devem buscar produzir com o menor nível de poluição, devastação e desperdício possível, buscando, assim, uma produção ecologicamente viável. 


\section{RESPONSABILIDADE SOCIAL NO BRASIL}

No Brasil, o movimento de valorização da responsabilidade social empresarial ganhou forte impulso na década de 90, através da ação de entidades não-governamentais, institutos de pesquisa e empresas sensibilizadas para a questão. $\mathrm{O}$ trabalho do Instituto Brasileiro de Análises Sociais e Econômicas - IBASE, na promoção do Balanço Social, é uma de suas expressões e tem logrado progressiva repercussão.

As enormes carências e desigualdades sociais existentes no país dão à responsabilidade social empresarial relevância ainda maior. Contudo, a globalização teve importância decisiva na ampliação da consciência coletiva, dado que os avanços tecnológicos vêm permitindo o trânsito instantâneo de informações, exigindo assim, elevado grau de transparência por parte dos órgãos públicos e privados.

Cabe às empresas privadas direcionar suas atividades no sentido de causar impactos positivos à sociedade na qual estão inseridas. A sociedade brasileira espera que as empresas cumpram um novo papel no processo de desenvolvimento: sejam agentes de uma nova cultura, sejam atores de mudança social, sejam construtores de uma sociedade melhor.

\subsection{Fatores que Impulsionaram a Adoção dos Conceitos e das Práticas de RSC Pelas Empresas}

\section{METODOLOGIA}

A percepção da existência da Responsabilidade Social Corporativa pelas empresas calçadistas exportadoras do Ceará está apoiada por um estudo multicaso, de caráter exploratório, iniciando-se com uma pesquisa bibliográfica e documental, para fornecer uma melhor compreensão sobre os conceitos e as práticas de Responsabilidade Social Corporativa, verificar os fatores que impulsionaram a adoção desses conceitos e práticas pelas empresas e examinar os objetivos das empresas na adoção dessas práticas. A pesquisa trata de estudo de natureza qualitativa.

A pesquisa qualitativa analisa os fenômenos com visão ampliada do contexto e tem por objetivo básico entender a natureza de um fenômeno social pela observação, pela riqueza de descrição, pela comparação e pela experimentação, baseando-se em objetivos classificatórios que permitem maior capacidade de reflexão, diferentemente da pesquisa quantitativa, que se apóia em números, correndo o risco de "se firmarem na exatidão fria da falta de contexto" (LEITE, 2004, p. 82).

As empresas estudadas são a GRENDENE S/A, a DAKOTA NORDESTE S/A e a VULCABRÁS DO NORDESTE S/A. A escolha foi feita com base na lista do Prêmio Delmiro Gouveia das melhores empresas cearenses em Responsabilidade Social, concedido pela Bolsa de Valores
Várias empresas, no Brasil, já vêm introduzindo variáveis sociais nas suas estratégias de gestão, visando a demonstrar à sociedade que, mesmo buscando a sustentabilidade dos negócios, também querem ajudar na solução dos problemas sociais e ambientais.

$\mathrm{Na}$ busca de atender essas demandas, é comum encontrar empresas, desenvolvendo projetos voltados para a conservação ambiental, criando fundações, promovendo ações comunitárias e instituindo códigos de ética para funcionários. O exercício da ética, da solidariedade e da partilha parece já fazer parte do cotidiano das comunidades mundiais com forte eco no seio das grandes corporações internacionais e, mais recentemente, das nacionais.

Outra importante vantagem consiste em que a responsabilidade social diminuiu a vulnerabilidade das empresas. Ao exibirem-se os desvios de condutas que podem afetar a credibilidade do negócio e ainda reduzir custo com as infrações, economizam-se tempo, trabalho, recursos financeiros, além de fortalecer a lealdade dos consumidores e dos colaboradores internos.

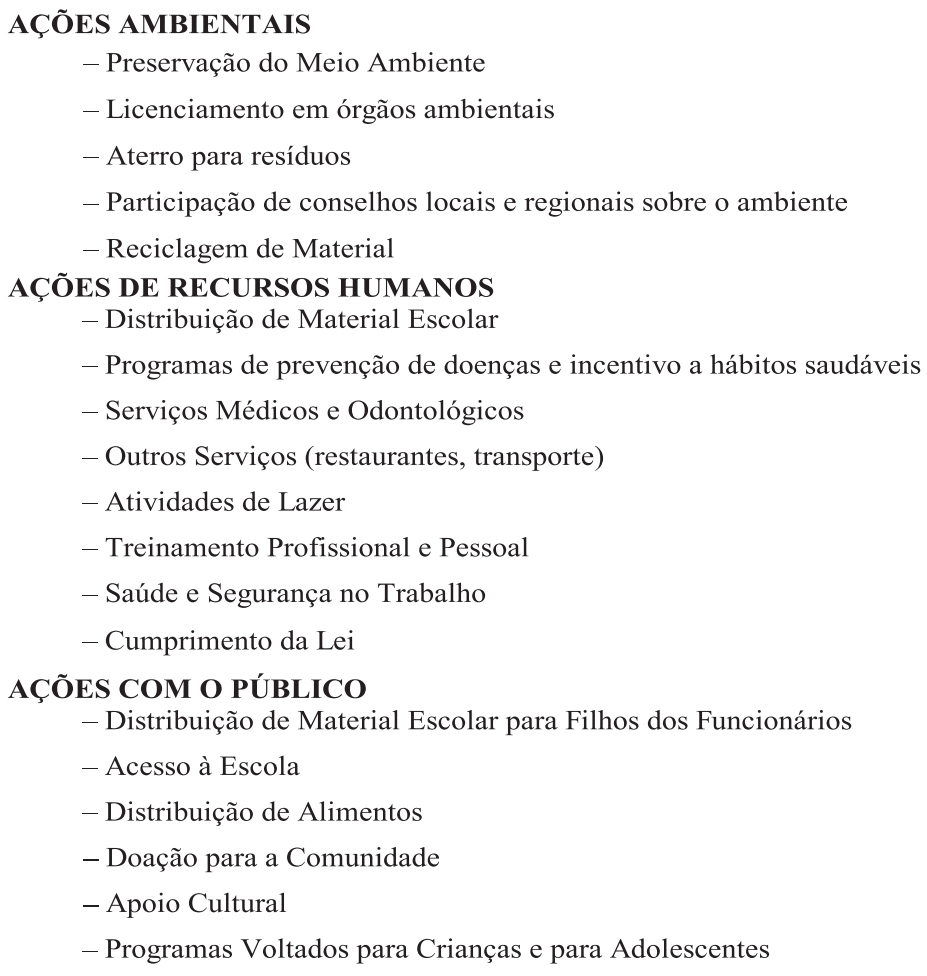

Quadro 1: Indicadores de Práticas de Responsabilidade Social Corporativa Fonte: elaborado pelos autores 
Regional, localizada no município de Fortaleza/CE, em que estas empresas aparecem entre as primeiras 50 (cinqüenta). O setor em que atuam é de grande importância para a economia do estado do Ceará, posicionado entre os cincos maiores do Brasil.

As áreas de análise usadas na pesquisa, para designar as práticas de Responsabilidade Social Corporativa, e que, portanto, norteou a busca de informações estão listadas no Quadro 1.

Eleitas as áreas de análise, a pesquisa documental dos conceitos e das práticas de responsabilidade social corporativa adotados pelas empresas selecionadas tomou como base os dados disponíveis livremente nos sites das empresas, nas demonstrações contábeis publicadas em meio impresso, bem como em outras publicações das referidas empresas acerca do assunto. Os dados coletados foram complementados com consultas telefônicas aos profissionais responsáveis pela elaboração e pela publicação das informações sociais das empresas pesquisadas e com visitas às empresas, para contato pessoal com esses profissionais. Portanto, as informações disponibilizadas nessa pesquisa não são de natureza sigilosa, encontrando-se em sua maioria acessíveis ao público externo em geral. Nas três empresas, essas informações eram de responsabilidade do setor de Recursos Humanos.

\section{ANÁLISE DOS CONCEITOS E DAS PRÁTICAS DE RESPONSABILIDADE SOCIAL CORPORATIVA ADOTADOS POR EMPRESAS EXPORTADORAS DO SETOR CALÇADISTA CEARENSE}

\subsection{Apresentação das Empresas Estudadas}

A Dakota foi fundada em 1977, na cidade de Nova Petrópolis (RS). O parque fabril se destaca pela grandiosidade e pelos produtos que fabrica diariamente, com capacidade produtiva de 75.000 pares de calçados. No Estado do Ceará, estão localizadas três unidades, nos municípios de Iguatu, Maranguape e Russas, totalizando 7 mil funcionários.

A Grendene foi fundada por Alexandre e Pedro Grendene Bartelle, em 1971, na cidade de Farroupilha (RS). Era uma pequena fábrica de embalagens plásticas, que, aos poucos, foi-se transformando. Atualmente, seu parque industrial possui tecnologia de ponta e fábricas de primeiro Mundo e segue normas internacionais de produção. No Estado do Ceará, são 7 unidades fabris em Sobral e um total de 13 unidades, totalizando 22 mil funcionários.

A Vulcabrás foi fundada em 1952, na cidade de São Paulo, iniciando no ano seguinte a produção de calçados de couro com sola de borracha vulcanizada. Em 1970, transformou-se em Sociedade Anônima de Capital Aberto e, em 1995, deu início à fabricação de calçados no Estado do Ceará, com sua subsidiária Vulcabrás do Nordeste S/A, no município de Horizonte. A empresa atua no seguimento de calçados para a prática de esportes e lazer, sapatos masculinos de couro e botas de borracha e PVC.

\subsection{Análise dos Indicadores de Responsabilidade Social das Empresas Grendene $S / A$, Dakota Nordeste $S / A$ e Vulcabrás do Nordeste $S / A$.}

A empresa GRENDENE S/A foi a única a publicar seu balanço social em meio de comunicação externo. Das outras empresas, foram colhidos dados através de seus sites, de contatos diretos e das publicações constantes do Prêmio Delmiro Gouveia.

No que tange aos indicadores de Responsabilidade Social Empresarial apresentados no Quadro 1, foram constatados algumas práticas.

\section{Ações ambientais}

\section{Preservação do Meio Ambiente}

A empresa DAKOTA NORDESTE S/A busca os melhores processos de trabalho, compartilhando com seus colaboradores o comprometimento de gestão ambiental, sempre visando à preservação do meio ambiente.

A GRENDENE S/A afirma não poluir o meio ambiente. Existe um programa dentro da empresa, denominado Jardinagem, que consiste do plantio e da manutenção de árvores, além de do plantio e da manutenção de jardins nas áreas internas e externas da empresa. Outro programa realizado é o Adote uma Praça. Neste programa, em parceria com a Prefeitura de Sobral (CE), a empresa mantém, sob seus cuidados, a Praça São João, um dos principais pontos de passeio da cidade.

A empresa VULCABRÁS DO NORDESTE S/A não informou sobre ações na referida área nem nos documentos consultados nem nas entrevistas.

\section{Licenciamentoem Órgãos Ambientais}

A DAKOTA NORDESTE S/A possui licença operacional junto à SEMACE que acompanha todos os procedimentos da empresa com o couro.

A VULCABRÁS DO NORDESTE S/A afirma atender a todos os requisitos legais do Conselho Nacional do Meio Ambiente - CONAMA -, do Instituto Brasileiro do Meio Ambiente - IBAMA - e da Legislação Estadual e portarias Secretaria Estadual de Meio Ambiente do Ceará - SEMACE.

A GRENDENE S/A não informou sobre sua relação com órgãos ambientais nem nos documentos consultados nem nas entrevistas.

\section{Aterropara Resíduos}

A DAKOTA NORDESTE S/A possui um aterro sanitário próprio, para colocar seus resíduos industriais, que é totalmente protegido e não traz impacto ambiental. 
A VULCABRÁS DO NORDESTE S/A lança seus resíduos no aterro municipal de Horizonte-CE, cidade na qual está localizada.

A GRENDENE S/A não informou possuir aterro para resíduos nem nos documentos consultados nem nas entrevistas.

\section{Reciclagem deMaterial}

A GRENDENE S/A reaproveita 99\% dos resíduos industriais. Toda a água do circuito produtivo e todo o PVC usado são reaproveitados. Há também um reaproveitamento de resíduos de pintura dentro da fábrica.

A VULCABRÁS DO NORDESTE S/A utiliza caixa de papelão reciclado, papéis, PVC e Borracha.

A DAKOTA NORDESTE S/A não informou sobre prática de reciclagem de material nem nos documentos consultados nem nas entrevistas.

\section{Ações de Recursos Humanos}

\section{Distribuição de Material Escolar}

A DAKOTA NORDESTE S/A distribui material escolar para seus funcionários que cursam os Ensinos Médio e Fundamental. Há também a distribuição deste material para os filhos dos funcionários que estão cursando o Ensino Fundamental.

A VULCABRÁS DO NORDESTE S/A possui uma biblioteca interna acessível a todos os funcionários.

A GRENDENE S/A não informou sobre prática de distribuição de material escolar nem nos documentos consultados nem nas entrevistas.

\section{Programas dePrevenção}

A DAKOTA NORDESTE S/A promove programas de prevenção da saúde através de palestras e exames rotineiros para seus funcionários.

A GRENDENE S/A possui um programa de prevenção de doenças e incentivo a hábitos saudáveis.

A VULCABRÁS DO NORDESTE S/A possui uma comissão interna de Prevenção de Acidentes - CIPA -, uma semana dedicada à Prevenção de Acidente do Trabalho e alguns simulados de emergência e treinamentos de segurança.

\section{ServiçosMédicose Odontológicos}

As empresas GRENDENE S/A, DAKOTA NORDESTE S/A e VULCABRÁS DO NORDESTE S/A possuem serviços médicos e odontológicos gratuitos para seus colaboradores.

\section{Serviços Extras}

A GRENDENE S/A disponibiliza, aos seus colaboradores, refeições com alimentação saudável e balanceada dentro de um padrão de qualidade e satisfação. Cestas bási- cas são distribuídas pela empresa, oferecendo 02 (duas) sacolas econômicas com gêneros alimentícios. Existe um convênio com 02 (duas) farmácias em Sobral, que oferecem $17,5 \%$ de desconto nas compras à vista e a prazo. Há também um convênio com 03 (três) óticas na cidade, para facilitar a compra de óculos de grau pelos seus colaboradores. Outro serviço extra oferecido é o de Empréstimos Pessoais, com o objetivo de apoiar seus funcionários diante de situações adversas relativas à moradia, à saúde e à educação. $A$ empresa mantém convênio com o Banco Bradesco, contando com um Posto de Atendimento e 04 (quatro) caixas eletrônicos. Um novo estacionamento foi construído pela empresa, que abriga automóveis, bicicletas e motocicletas.

A VULCABRÁS DO NORDESTE S/A possui refeitório para seus funcionários e quiosques equipados com televisores, lanchonete e biblioteca.

A DAKOTA NORDESTE S/A não informou possuir serviços extras para seus funcionários nem nos documentos consultados nem nas entrevistas.

\section{Atividades de Lazer}

A DAKOTA NORDESTE S/A realiza atividades esportivas constantemente, como voleibol, futebol society, gincanas educativas e culturais. Atua na realização de eventos comemorativos na Páscoa, no Dia da Criança e no Natal, envolvendo, principalmente, a participação dos filhos dos colaboradores. Existem corais em todas as unidades, e a ginástica laboral é praticada em quase todas as atividades.

A GRENDENE S/A possui um espaço, em suas instalações, para lazer e para descanso de seus colaboradores. A empresa mantém uma doação mensal ao time representante da cidade nas competições futebolísticas estaduais e nacionais, o Guarany Sporting Club.

A VULCABRÁS DO NORDESTE S/A possui quiosques equipados com televisores, lanchonete e biblioteca.

\section{Politicas de Treinamento}

A GRENDENE S/A desenvolve campanhas socioeducativas que abordam questões relacionadas ao tema saúde. A realização deste tipo de campanha envolve palestras em sala de treinamento, faixas educativas na portaria das fábricas, chamadas de som dos restaurantes, painéis educativos, distribuição de panfletos na cesta básica, outdoors internos, além de parcerias com órgãos públicos.

A VULCABRÁS DO NORDESTE S/A possui programas de treinamento, em particular, com seus Gestores. Com seus funcionários, ela possui vínculo com a universidade, obtendo descontos para os mesmos, além de convênio com o SESI/SENAI, promovendo cursos internos e custeando cursos externos.

A DAKOTA NORDESTE S/A não informou sobre suas políticas de treinamento nem nos documentos consultados nem nas entrevistas. 


\section{Saúdee Segurançano Trabalbo}

A empresa GRENDENE S/A possui uma equipe de médicos, engenheiros, enfermeiras e técnicos especializados em Segurança e Medicina do Trabalho, engajados em treinar, orientar e capacitar os colaboradores, bem como realizar inspeções e investigações para melhorar o local de trabalho.

A VULCABRÁS DO NORDESTE S/A possui dois programas nessa área: PPRA - Programa de Prevenção de Riscos Ambientais - e PCMSO - Programa de Controle Médico e Saúde Ocupacional.

A DAKOTA NORDESTE S/A não informou sobre possuir programas de saúde e segurança no trabalho nem nos documentos consultados nem nas entrevistas.

\section{CumprimentodaLei}

As empresas GRENDENE S/A e DAKOTA NORDESTE S/A são rígidas no cumprimento da lei. Há portadores de deficiência e pessoas negras em seus quadros funcionais, inclusive em cargos de chefia. A Grendene não admite menores de 16 anos em seu quadro funcional.

A VULCABRÁS DO NORDESTE S/A possui apenas portadores de deficiência em seu quadro funcional.

\section{Ações com o Público}

Distribuição de Material Escolarpara Filhos de Funcionários

A DAKOTA NORDESTE S/A é a única empresa que distribui material escolar aos filhos de seus colaboradores, que estão cursando o Ensino Fundamental. A Grendene e a Vulcabrás não utilizam esta prática.

\section{Acessoà Escola}

A empresa GRENDENE S/A disponibiliza vagas reservadas às mães trabalhadoras. Os filhos podem estudar em creches e em escolas conveniadas com a empresa. Tanto a GRENDENE S/A quanto a DAKOTA NORDESTE S/A estimulam os funcionários e os dependentes à alfabetização. A primeira ganhou, inclusive, o troféu V Semana da Alfabetização, pela sua parceria no Projeto Alfabetização Solidária.

A VULCABRÁS DO NORDESTE S/A disponibiliza creche para os filhos dos funcionários.

\section{Doaçãoparaa Comunidade}

A DAKOTA NORDESTE S/A promove doações junto a escolas da comunidade. São doados televisores, livros e computadores, além de apoio à melhoria da infraestrutura e incentivos a lazer e a esporte. A empresa também doa alimentos para as camadas menos favorecidas e trabalha no engajamento em campanhas municipais, com o objetivo de valorizar a sociedade.

A GRENDENE S/A está fazendo a doação, entre os anos de 2003 e 2005, de 3.000 .000 (três milhões) de pares de calçados para crianças de escolas públicas do Estado do
Ceará. Em parceria com a NUTRINOR, empresa que terceiriza os restaurantes das fábricas, são doados, diariamente, vários litros de sopa à Casa do Bom Samaritano. São doadas, também, 10 (dez) cestas básicas por mês para a Casa da Mamãe, que tem como objetivo abrigar as mães carentes de Sobral e de outras localidades que possuem recém-nascidos. Outra campanha feita por esta empresa é a Campanha de Donativos "Natal sem Fome". No mês de dezembro, são arrecadadas quantidades expressivas de alimentos, além de roupas, calçados e brinquedos, que são entregues ao Padre João Batista Frota, precursor da campanha.

A empresa VULCABRÁS DO NORDESTE S/A afirma também fazer doações de Cestas Básicas para a comunidade, em particular para as famílias mais necessitadas. A empresa também incentiva seus funcionários a fazerem doações, quando é solicitada ajuda para famílias carentes, através da confecção de cartazes com pedidos de ajuda para quem precisa.

\section{Apoio Cultural}

Com o objetivo de incentivar a cultura, a DAKOTA NORDESTE S/A apóia grupos de dança, como o Grupo de Danças Gauchescas, o Grupo de Pagode e o Grupo de Dança de Salão.

A VULCABRÁS DO NORDESTE S/A patrocina eventualmente práticas de esporte na região em que está localizada.

Já a GRENDENE S/A não utiliza o apoio cultural como projeto social para o público externo.

Programas Voltados para Crianças e para Adolescentes

A GRENDENE S/A realiza programas voltados para crianças carentes e a DAKOTA NORDESTE S/A realiza programas voltados para adolescentes das comunidades menos favorecidas, objetivando valorizar a sociedade.

A VULCABRÁS DO NORDESTE S/A não realiza programas com crianças e adolescentes.

\subsection{Discussão dos dados}

As empresas estudadas, em geral, voltam suas ações sociais para seu público interno. Como se pode ver nos dados mencionados, existem mais tópicos nas ações com seus funcionários que nas demais. Com exceção da GRENDENE $\mathrm{S} / \mathrm{A}$, que tem consideráveis ações com o público externo.

Em relação ao meio ambiente, em geral, as empresas visam atender a legislação, com exceção da GRENDENE $\mathrm{S} / \mathrm{A}$, que não menciona sua situação perante os órgãos ambientais. Por outro lado, esta empresa recicla quase a totalidade dos seus resíduos, diminuindo os custos de sua produção e evitando jogar tais dejetos no meio ambiente. A DAKOTA NORDESTE S/A demonstra preocupação com essa área ambiental, tendo em vista que possui um aterro 
sanitário próprio e o acompanhamento pela SEMACE das suas ações ambientais.

No que tange às ações com o público interno, podese constatar a preocupação das empresas com seu quadro funcional. Vários projetos são desenvolvidos, visando à motivação dos funcionários e ao seu bem-estar social, com destaque para a GRENDENE S/A e para a VULCABRAS DO NORDESTE S/A, que atuam em praticamente todos os requisitos pesquisados.

Já nas ações com o público externo, pode-se constatar, em geral, que as empresas utilizam a prática de doação para entidades filantrópicas ou para a comunidade do seu entorno. Nesta seção, ganha destaque a empresa GRENDENE S/A, que atua diretamente nas comunidades do seu entorno, com doação de milhares de pares de sapatos, sopa e cestas básicas para entidades filantrópicas, dentre outras ações.

\section{CONCLUSÃO}

Constatou-se, com a pesquisa, que a adoção dos conceitos de responsabilidade social corporativa e as ações praticadas pelas empresas cearenses estudadas resultam no crescimento de seus negócios e na sua continuidade, fazendo com que elas ocupem posição de destaque, além de atingir as exigências do mercado competitivo.

Percebeu-se, ao analisar as ações de responsabilidade social corporativa, que as empresas estudadas têm como objetivo o marketing e a produtividade. A maioria dessas ações visa beneficiar seus funcionários e a comunidade em que a empresa atua, melhorando, assim, o nível de satisfação dos seus colaboradores e a imagem da empresa perante a sociedade em que atua bem como aumentando sua produtividade.

O pressuposto de que a adoção de conceitos e práticas de responsabilidade social corporativa objetiva, principalmente, melhorar a imagem e a produtividade interna das empresas foi confirmado nas empresas estudadas, uma vez que as ações de RSC praticadas resultam em vantagens.

A participação dessas empresas no Prêmio Delmiro Gouveia e sua classificação entre as 50 que mais investem em Responsabilidade Social mostram a intenção de divulgação dessas práticas de RSC, caracterizando, assim, o uso do Marketing Social e objetivando a melhoria da imagem da empresa perante seus clientes. A utilização dessa ferramenta pode impactar no aumento de vendas.

Não se pode deixar de destacar o vetor ético da RSC das empresas estudadas, que trabalham de acordo com as leis e visam ao bem-estar daqueles que participam diretamente dos seus trabalhos.

O lado socioambiental também merece destaque, apesar de não ser tão marcante quanto o marketing e a produtividade. As empresas estudadas evitam desperdícios e procuram agir corretamente no ponto de vista ecológico, sendo licenciadas pelos órgãos ambientais. De forma geral, elas investem no bemestar social da comunidade na qual estão inseridas.

É importante que todos se conscientizem de que a responsabilidade social é realmente necessária. Não só para a empresa, mas também para toda a sociedade.

\section{REFERÊNCIAS BIBLIOGRÁFICAS}

BERNA, Vilmar. Comoadministrarcom responsabilidadeambiental. Disponível em http://www.jornaldomeioambiente.com.br// GestãoAmbiental/ResponsabilidadeAmbiental.asp\#poli Acesso em 24/06/2005.

BIANCHINI, M. Perchè alle organizzazioni del XXI secolo se chiede di essereSocialmenteResponsabili? In chemodopossono realizzare un comportamento etico e come possono comunicarlo? Disponível em <http:/ / www.datamanager.it $/$ itconsult.php? edricercato $=9737>$. Acessado em 02/03/2005.

CARROL I, A.A Atree-dimensional conceptual model of corporateperfomance. The Academy of Management Review. v.4. p. 17-25, 1979.

ETHOS, Instituto Ethos de Empresas e Responsabilidade Social. Disponível em < www.ethos.org.br $>$ Acesso em 05/03/2005.

FISCHER, R.M. et al. Sustentabilidade sócio-ambiental através de alianças estratégicas intersetoriais. CONFERENCIA REGIONAL DE AMÉRICA LATINA E DEL CARIBE DE ISTR, V, Lima. Anais...Lima: Universidad Ricardo Palma, 2005.

FORMENTINI, M. A Percepção dos stakeholders sobre a responsabilidadesocial e a sua contribuição para a imagem empresarial: um estudo de caso na John Deere Brasil Ltda - borizontina - RS. Dissertação (Mestrado em Desenvolvimento, Gestão e Cidadania). Programa de Pós-Graduação em Desenvolvimento, Gestão e Cidadania. Disponível da Universidade Regional do Noroeste do Estado do Rio Grande do Sul - UNIJUí, 2004.

KOTLER, Philip. Administração de marketing. 10.ed. São Paulo: Prentice Hall, 2000.

—.Marketing para organizações que não visam lucro. São Paulo: Atlas, 1978.

IPEA, Instituto de Pesquisa Econômica Aplicada. Disponível em $<$ www.ipea.gov.br> Acesso em 02/06/2001.

LEITE, Francisco Tarciso. Metodologia científica: iniciação à pesquisa científica, métodos e técnicas de pesquisa, metodologia do trabalho científico. Fortaleza: Universidade de Fortaleza, 2004.

LOURENÇO, Alex Guimarães; SCHRÖDER, Débora de Souza. Vale investir em responsabilidade empresarial? Stakeholders, ganhos e perda Responsabilidade Social das Empresas: a contribuição das universidades. São Paulo: Petrópolis, 2003.

MELONETO, F. FROES. Gestão da responsabilidadesocial corporativa: o caso brasileiro. Rio de Janeiro: Qualitymark, 2001.

MELO NETO, F. FROES, C. Responsabilidade social \& cidadania empresarial. 2.ed. Rio de Janeiro: Qualitymark, 2001.

OLIVEIRA, M.C. et al. Análise das ações de responsabilidade social empresarial divulgadas nas demonstrações contábeis das distribuidoras de energia do Grupo Empresarial Guaraniana S.A. se- 
gundo modelo analítico de Hopkins. CONGRESSO USP DE CONTROLADORIA E CONTABILIDADE, 4, 2004, São Paulo. Anais... São Paulo: USP, 2004.

PEIXOTO, Marina Costa Cruz. Responsabilidade social e o impacto no comportamento do consumidor. Disponível em http:// www.ethos.org.br/_Ethos/Documents/PEVResponsabilidade $\% 20$ Social $\% 20 \mathrm{e} \% 20$ Impacto $\% 20 \mathrm{no} \% 20$ Compottamento $\% 20 \mathrm{do}$ \%20Consumidor.doc. Acessado em 13/04/2005

SAGE - Laboratório de Sistemas Avançados de Gestão da Produção. Responsabilidade social empresarial. Disponível em <http:/ /www.sage.coppe.ufrj.br/rs_empresarial.html>. Acesso em 20/ $12 / 2004$.

TACHIZAWA, T. Gestão ambiental eresponsabilidade social corporativa. São Paulo: Atlas, 2002.

TENÓRIO, F. Responsabilidadesocial empresarial. Rio de Janeiro: FGV, 2004.

VASCONCELOS, Ana Maria de. Responsabilidade social empresariale o desenvolvimento comunitário sustentável. Dissertação (Mestrado em Administração). Universidade de Fortaleza - UNIFOR, 2002. 